\title{
UMA PERSPECTIVA DE ENSINO A PARTIR DA TEORIA DO CORPO EM MERLEAU-PONTY
}

\author{
Huanderson Barroso Lobo ${ }^{1}$ \\ Ronara Viana Cordovil ${ }^{2}$ \\ José Vicente De Souza Aguiar ${ }^{3}$
}

\begin{abstract}
RESUMO
O ensino historicamente no Brasil foi construído a partir de práticas instrucionistas e reprodutivas. Diante desta perspectiva, verificou-se a necessidade de realizar um estudo no sentido de compreender as possibilidades de ensino a partir de uma perspectiva fenomenológica. Merleau-Ponty desde sua primeira obra, procura superar a visão anterior de que o corpo é apenas um objeto, colocando-o como um corpo-sujeito. Ele é o veículo do ser no mundo, faz-se presente em um meio definido, integrando-se a ele. $\mathrm{O}$ autor faz de sua teoria da percepção uma teoria do corpo, pois este estabelece a condição de possibilidade do perceber. Como instrumentos da pesquisa foram utilizados as leituras bibliográficas de diversas obras do referido autor, de modo a articulá-las às atividades de ensino, possibilitando a utilização do corpo nas experiências educacionais, que para Merleau-Ponty são fundamentais na construção do conhecimento.
\end{abstract}

Palavras-Chave: Fenomenologia. Corpo. Conhecimento. Merleau-Ponty.

\section{TEACHING PERSPECTIVE FROM MERLEAU-PONTY'S BODY THEORY}

\begin{abstract}
Teaching historically in Brazil, was constructed from instructional and reproductive practices. From this perspective, it was verified the need to carry out a study in the sense of understanding the possibilities of teaching from a phenomenological perspective. MerleauPonty since his first work, seeks to overcome the previous view that the body is only an object, placing it as a subject body. He is the vehicle of being in the world, becomes present in a definite medium, integrating with it. The author makes of his theory of the perception a theory of the body, because this establishes the condition of possibility of perceiving. As instruments of the research were used the bibliographical readings of several works of the said author, in order to articulate them to teaching activities, making possible the use of the body in educational experiences, which for Merleau-Ponty are fundamental in the construction of knowledge.
\end{abstract}

\footnotetext{
${ }^{1}$ Mestrando do Programa de Pós-Graduação em Educação e Ensino de Ciências na Amazônia da Universidade do Estado do Amazonas.

${ }^{2}$ Mestranda em Educação e Ensino de Ciências na Amazônia. Universidade do Estado do Amazonas - Normal Superior - UEA/ENS, Brasil.

3 Professor Doutor do Programa de Pós-Graduação em Educação e Ensino de Ciências na Amazônia. Universidade do Estado do Amazonas. Manaus, Amazonas.
} 
Keywords: Phenomenology. Body. Knowledge. Merleau-Ponty.

\section{INTRODUÇÃO}

Procuramos refletir com base na fenomenologia existencial de Merleau-Ponty, que tem cunho antropológico e apresenta a relação do ser com o mundo, onde as experiências são essenciais na construção do conhecimento. Para Moreira (2004), existem várias e não uma única fenomenologia. Neste artigo não pretendemos buscar a essência dos fenômenos como acontece na fenomenologia de Husserl em seu idealismo transcendental, tampouco conceber a ontologia do ser no mundo, a qual Heidegger fundamenta, buscaremos entender a relação do ser real e como este processo pode contribuir para uma perspectiva fenomenológica de ensino.

Segundo Dartigues (1973), Fróis (2001) e Marin (2008), as principais características do pensamento de Merleau-Ponty são a existência do mundo independentemente das considerações que se possam fazer dele; inseparabilidade entre sujeito e seu mundo (objeto), bem como a construção recíproca entre eles; o corpo como conexão do sujeito ao seu mundo; percepção do espaço como expressão da vida total do sujeito e a interconexão entre consciência humana e mundo pela percepção.

A fenomenologia, para Merleau-Ponty, também busca a valorização dos sentidos; as percepções são abordadas não como uma representação mental, mas sim como uma dimensão da existência humana, circunscrita na facticidade do ser. Essa atividade perceptiva, para o autor, é revelada pelos sentidos e pela experiência de vida. Pela percepção tudo se concebe, e aquilo que é sentido antes de qualquer análise vai ao confronto das ideias construídas e idealizadas na ciência, conforme seus relatos na obra Fenomenologia da Percepção (1999)4:

\footnotetext{
Retornar às coisas mesmas é retornar a este mundo anterior ao conhecimento do qual o conhecimento sempre fala, e em relação ao qual toda determinação científica é abstrata, significativa e dependente, como a geografia em relação à paisagem primeiramente nós aprendemos o que é uma floresta, um prado ou um riacho. (1999, p. 4).
}

É através da percepção que um indivíduo organiza e interpreta as suas impressões sensoriais para atribuir significado ao seu meio. A percepção, para o autor, "não é uma ciência

\footnotetext{
${ }^{4}$ Todas as citações referentes ao ano de 1999 são retiradas da obra Fenomenologia da Percepção.
} 
do mundo, não é nem mesmo um ato, uma tomada de posição deliberada; ela é o fundo sobre o qual todos os atos se destacam e ela é pressuposta por eles" $(1999$, p. 6).

Merleau-Ponty ao estudar o ser, atribui características existenciais a sua relação ao mundo fenomênico, estabelece uma conexão de inseparabilidade da carne e da alma, pois para ele enquanto sou consciência, também sou parte do mundo: "é isto mesmo que nós representamos não como homens ou como sujeitos empíricos, mas enquanto somos todos uma única luz e enquanto participamos do uno sem dividir" (1999, p. 9).

O ser é quem vinvencia o mundo, ao fazê-lo pensar e perceber, atribui significados que são subjetivos, essa sinesia, o autor considera um "retorno às coisas mesmas". As experiências vividas são um exercício natural e individual do ser, a percepção se dá antes de ser capturada pela consciência e concebida pelo conhecimento.

A percepção para Merleau-Ponty é entendida como elemento inaugural do conhecimento, na qual a apreensão do sentido se faz pelo corpo, tornando este processo único e intransferível. É no plano das experiências que conseguimos denominar, associar e atribuir significados a tudo que foi percebido durante dado momento.

O autor ao abordar a sensação, renuncia a defini-la como impressão pura, pois entende que o ver é obter cores ou luzes, ouvir é obter sons e o sentir é obter qualidades, e para saber o que é sentir não basta ter visto ou ouvido algo, a sensação é algo individual e subjetivo e o próprio percebido só é evidentemente acessível através da percepção, que ocasionará uma experiência, e o que foi captado poderá ou não ser internalizado.

O ser é tocado pelo mundo e através dos seus sentidos ele interioriza as imagens, os sons e as sensações, isso proporciona o seu entendimento com o mundo. Dessa forma, toda e qualquer sensação pode produzir significados. E ao longo de sua vida, ele consegue identificar, pois também é responsável por sua criação e execução.

Ao desenvolvermos atividades que aproximem e estimulem o aluno a ter contato com o objeto estudado, estamos criando estratégias pautadas na fenomenologia, pois o sensível é aquilo que se apreende com os sentidos, "o aparelho sensorial não é um condutor, que mesmo na periferia a impressão fisiológica se encontra engajada em relações consideradas outrora como centrais" (1999, p. 32). Para o autor:

[...] é preciso aproximar-se mais diretamente dessa intencionalidade, examinando a noção simétrica de uma forma da percepção e, particularmente, a noção de espaço [...] O espaço não é ambiente (real ou lógico) em que as coisas se dispõem, mas o meio pelo qual a posição das coisas se torna possível (MERLEAU-PONTY, 1999, p. 327 - 328). 
Na educação formal, somos estimulados a dominar conteúdos, fazemos parte de uma educação voltada para a "cabeça", perpassando a ideia de que conhecer teorias garantem uma boa educação. Porventura, com essa forma de ensino, não estamos produzindo ainda mais reprodutores da objetividade? Desestimulando a imaginação científica, a curiosidade, visto que o conhecimento é apresentado aos estudantes como um produto acabado, pronto quase que definitivamente. Além do mais, o processo de produção do conhecimento com seus erros e acertos desaparece no ensino.

Podemos nos questionar então, por que seria importante envolver o corpo na educação? Em uma perspectiva fenomenológica, nossa consciência não é apenas um atributo mental, mas também fruto de nosso envolvimento corporal com o mundo, o que MerleauPonty (1999) denominou de corporalidade, o que nos faz pensar que os processos de aprendizagens requerem experiências cognitivas e corporais, e que a aprendizagem do ser tem relação com os desdobramentos sensoriais que estabelecemos com o mundo real, como ele afirma:

\begin{abstract}
Eu não sou o resultado ou o entrecruzamento de múltiplas causalidades que determinam meu corpo e meu "psiquismo", eu não posso pensar-me como uma parte do mundo, como o simples objeto da biologia, da psicologia e da sociologia, nem fechar sobre mim o universo da ciência. Tudo aquilo que sei do mundo, mesmo por ciência, eu o sei a partir de uma visão minha ou de uma experiência do mundo sem a qual os símbolos da ciência não poderiam dizer nada. Todo o universo da ciência é construído sobre o mundo vivido, e se queremos pensar a própria ciência com rigor, apreciar exatamente o seu sentido e seu alcance, precisamos primeiramente despertar essa experiência do mundo da qual ela é a expressão segunda. A ciência não tem e não terá jamais o mesmo sentido de ser que o mundo percebido, pela simples razão de que ela é uma determinação ou explicação dele (MERLEAU-PONTY, 1999, p. $3)$.
\end{abstract}

O autor para conceber seu 'cogito'5 que é o pensamento de fato e ser no mundo, chamado também de cógito tácito, analisou o corpo como instrumento de conexão, todavia as concepções vigentes eram outras. Na história da humanidade vamos perceber que o corpo sempre foi objeto de observações, experiências e estudos.

$\mathrm{Na}$ Grécia antiga, aparecem imagens de corpos fortes para o combate; com o cristianismo, observamos que o corpo era reprimido, humilhado e desprezado e ao mesmo

\footnotetext{
${ }^{5}$ Merleau-Ponty no capítulo intitulado "O Cogito" do seu livro Fenomenologia da Percepção, tenta entender o cogito cartesiano e mostrar os erros cometidos por Descartes e constrói um novo cogito, chamado de cogito tácito que é a condição sem a qual eu não poderia projetar em torno dos dados de minha experiência espacial. Não fosse por esse cogito, eu não poderia repetir, menos ainda reformular meus movimentos e gestos já estabelecidos.
} 
tempo glorificado, já o corpo feminino era visto como inferior ao masculino. Para Platão, o corpo era a prisão da alma, ou seja, duas existências distintas. Descartes aborda o corpo apenas como matéria física e, por isso, tem propriedades comuns a qualquer matéria, como tamanho, peso e capacidade motora.

O empirismo restringe a extensão corpórea às forças deterministas da natureza, esse pensamento do senso comum perpassa a ideia de que a pessoa não é responsável pelo seu próprio destino, passando a ser determinada por fatores externos. Podemos dizer que esta é também a concepção do positivismo6, que caracteriza o conhecimento como algo que só seria possível, então, por meio da observação dos fenômenos em seu contexto físico e palpável. Nietzsche, na contramão das concepções anteriormente descritas, valoriza o corpo, entendido como fio condutor para a compreensão de todas as questões humanas.

A fenomenologia existencial, a qual discutimos neste artigo, critica o pensamento cartesiano e os demais que não consideram a percepção e o corpo como partes integrantes do processo de construção do conhecimento. Em uma concepção fenomenológica, o corpo age como um todo, não isola seus sentidos. O tato, paladar, olfato, visão e audição interrelacionam-se, pois esses sentidos participam do mesmo corpo.

É através do corpo que temos consciência do mundo. Merleau-Ponty em uma de suas primeiras obras: A Estrutura do Comportamento (1942), procura superar a visão anterior de que o corpo é apenas um objeto, colocando-o como um corpo-sujeito. Ele é o veículo do ser no mundo, faz-se presente em um meio definido, integrando-se a ele. O autor faz de sua teoria da percepção uma teoria do corpo, pois este estabelece a condição de possibilidade do perceber.

O corpo e o mundo são inseparáveis, sendo que o corpo é o instrumento pelo qual podemos perceber o mundo; descentrando a ideia do racionalismo, Merleau Ponty (1999) destaca o corpo e lhe atribui centralidade nas escolhas que fazemos, permitindo através dele realizar ações e atribuir significados aos acontecimentos: "Eu fantasio acerca das coisas, imagino objetos ou pessoas cuja presença aqui não é incompatível com o contexto e, todavia eles não se misturam ao mundo, eles estão adiante do mundo, no teatro do imaginário" (p. 6).

Merleau-Ponty (1999) aponta que as interações entre sujeito e objeto, ou melhor, corpo e mundo, são essenciais para que os sentidos percebam as manifestações que acontecem

\footnotetext{
${ }^{6}$ A principal ideia do positivismo era a de que o conhecimento científico devia ser reconhecido como o único conhecimento verdadeiro. O principal idealizador do movimento positivista foi o pensador francês Auguste Comte (1798-1857), ganhando destaque internacional entre metade do século XIX e começo do XX.
} 
nas experiências. É a partir do corpo-vivido que posso estar no mundo em relação aos outros e as coisas:

\begin{abstract}
Se é verdade que tenho consciência de meu corpo através do mundo, que ele é, no centro do mundo, o termo inapercebido para o qual todos os objetos voltam a face, é verdade, pela mesma razão, que meu corpo é o 'pivot' do mundo; sei que os objetos têm várias faces porque poderia fazer a volta ao redor deles, e neste sentido tenho consciência do mundo devido a meu corpo (MERLEAU-PONTY,1999, p. 122).
\end{abstract}

O corpo deixa de ter sentido fisiológico e passa a ser existencial/essencial corroborando para a aprendizagem, ele está voltado ao mundo numa atividade perceptiva, não é um simples objeto e nem está no espaço, mas ele é a centralidade entre os objetos, é a "textura comum de todos os objetos e é, pelo menos em relação ao mundo percebido, o instrumento geral de minha “compreensão"” (MERLEAU-PONTY, 1999, p. 315).

A fenomenologia como elemento cognitivo de formação do pensamento pode ser compreendida na relação do ser no mundo, ou seja, na sua facticidade onde a consciência surge, isto é, pela sua existência e experiências vividas. Deveríamos então pensar que a construção do conhecimento pelo ser humano passa pelo modo como utilizamos o corpo e seus atributos diante do mundo.

\footnotetext{
A necessidade de passar pelas essências não significa que a filosofia as tome por objeto, mas, ao contrário, que nossa existência está presa ao mundo de maneira demasiado estreita para conhecer-se enquanto tal no momento em que se lança nele, e que ela precisa do campo da idealidade para conhecer e conquistar a sua facticidade (MERLEAU-PONTY, 1999, p. 11-12).
}

Podemos entender que o conhecimento, para o autor, está na capacidade de perceber o que nos rodeia, dando significado aos fenômenos assimilados pelos sentidos, "o mundo não é aquilo que eu penso, mas aquilo que eu vivo; estou aberto ao mundo, comunico-me indubitavelmente com ele, mas não o possuo, ele é inesgotável” (1999, p. 14). Esta atitude posta no processo de ensino estimula a criança ao ato de pensar a assimilação e produção do conhecimento como um fato processual, visto que tanto o pensamento quanto a produção da ciência são históricos e passíveis de novas compreensões.

Se o mundo é aquilo que nós percebemos e o nosso corpo faz a conexão com o espaço, podemos entender que as possibilidades de ensino a partir de uma perspectiva fenomenológica, são possíveis, considerando que a percepção pode ser ampliada nos espaços 
de ensino, além disso, os alunos são convidados a expressarem suas compreensões possíveis, caracteristicamente inacabadas.

O princípio da intencionalidade torna possível a realização de atividades voltadas à busca de objetivos conceituais, procedimentais e atitudinais, pois o aluno tem autonomia para buscar aquilo que é posto diante dos sentidos. Dentro do campo da fenomenologia, este termo foi definido por Husserl como "toda consciência é consciência de alguma coisa" (HUSSERL, 2008, p. 17). Heidegger (1992) diz que a intencionalidade se edifica, tendo em vista a correspondência que uma figura de consciência sempre possui com o fenômeno que objetivamente lhe encontra-se correlato, mas que, por sua vez, também só se constitui em meio ao acontecimento.

Para Merleau-Ponty a consciência ou sujeito é o corpo. O primeiro modo de ser da noção de intencionalidade usada e descrita por ele é a noção de "intencionalidade motora" (1999, p. 159), sendo o corpo a potência de um certo mundo. Comentado em um caso específico pelo autor:

\footnotetext{
O que lhe falta não é nem a motricidade nem o pensamento, e somos convidados a reconhecer, entre o movimento enquanto processo em terceira pessoa e o pensamento enquanto representação do movimento, uma antecipação ou uma apreensão do resultado assegurada pelo próprio corpo enquanto potência motora, um 'projeto motor' (Bewegungsentwurf), uma 'intencionalidade motora' (1999, p. 159).
}

$\mathrm{O}$ autor chama esse ciclo de arco intencional, pelo qual o indivíduo encontra-se completamente situado. "É esse arco intencional que faz a unidade entre os sentidos, a unidade entre os sentidos e a inteligência, a unidade entre a sensibilidade e a motricidade. É ele que se 'distende' na doença” (1999, p. 190).

Merleau-Ponty recupera a natureza intencional da percepção, com isso, o pensamento cartesiano e kantiano sobre a noção de intencionalidade operante é contestada. Cabe ressaltar que não somente ele, mas toda a tradição fenomenológica, principalmente a francesa, faz oposição ao pensamento objetivo da ciência, criticando o conceito de intencionalidade, proposto anteriormente.

$\mathrm{O}$ autor, nos desdobramentos de seus estudos, busca compreender o mundo vivido, retratando o sentido primeiro da experiência, criticando a razão científica e instrumental. Correndo riscos a ir contra o pensamento clássico, suspendendo seus juízos tomados como certos, Merleau-Ponty fez de sua prática filosófica uma retomada permanente da experiência perceptiva ou do retorno às coisas mesmas. 
$\mathrm{Na}$ fenomenologia Merleau-pontyana a intencionalidade da consciência é concebida na extensão de nosso corpo, mediante a essa intencionalidade da consciência todos os atos, os gestos, os hábitos, qualquer ação humana tem um significado, exercendo papel fundamental na compreensão e atribuição do significado para as coisas. Sem estes significados, não se poderia estabelecer signos e sentido aos objetos.

E este princípio se estabelece em uma dada temporalidade que nos conduz à subjetividade, visto que de imediato todas as nossas experiências, enquanto são nossas, dispõem-se segundo o antes e o depois, o autor estabelece que "analisar o tempo não é tirar as consequências de uma concepção preestabelecida da subjetividade, é ter acesso, através do tempo, à sua estrutura concreta" (1999, p. 550).

Ao analisarmos uma abordagem fenomenológica acerca do ensino, entendemos que a percepção, o corpo, a facticidade e a intencionalidade podem ser trabalhadas e instituídas na realização de atividades de produção do ensino, colaborando na construção e ampliação do conhecimento, tanto dos docentes quanto dos alunos.

Vejamos então exemplos de recursos pedagógicos e desses princípios fenomenológicos que podem ser utilizados nas disciplina curriculares da educação formal. Ressaltamos que nas obras de Merleau-Ponty não há imposições de procedimentos específicos. Realizaremos um deslocamento conceitual embasados no princípio da intencionalidade fenomenológica que nos permite caracterizar qualquer atividade humana a essa teoria.

\section{DESENHOS, FENOMENOLOGIA E O ENSINO}

A palavra "desenho" tem origem do latim e vem da palavra "desígnio", que significa projeto, plano ou propósito e confunde-se com o desejo. Para Francastel (1987), “os desenhos são imagens, representações das realidades que são interpretadas pelos indivíduos como pertencentes a uma dada cultura". Na arte rupestre, foram realizados os primeiros desenhos que se têm notícia na história humana.

Os desenhos exercem uma forma de linguagem não-verbal, representam algo concreto ou abstrato, geralmente têm relação com o mundo visível. Se na fenomenologia somos um ser que se envolve com o mundo a sua volta, na prática desta arte podemos conceber aquilo que percebemos diante das experiências vividas.

Isso quer dizer que minha construção gráfica não é, assim como os traços que a criança acrescenta arbitrariamente ao seu desenho e que a cada vez subvertem sua 
significação ("é uma casa, não, é um barco, não, é um velhinho"), uma reunião de linhas nascidas fortuitamente sob minha mão. De um lado ao outro da operação, é do triângulo que se trata. A gênese da construção não é apenas uma gênese real, ela é uma gênese inteligível, eu construo segundo regras, faço com que na figura se manifestem propriedades, quer dizer, relações que dizem respeito à essência do triângulo, e não, como a criança, todas aquelas sugeridas pela figura nãodefinida que existe de fato no papel. (MERLEAU-PONTY, 1999, p. 513).

O adulto, ao observar o desenho de uma criança, pode não assimilar o que foi desenhado, pois a criança não desenha o que vê, mas o que percebe das coisas, ou seja, o desenho apresenta aquilo que foi significativo a sua percepção. Ele expressa, assim, uma relação da criança com o meio e com o outro, trazendo à realidade um ato de sua percepção.

$\mathrm{O}$ autor realiza uma analogia no processo do desenho infantil com o desenvolvimento da fala. Na primeira fase, a criança apenas imita a linguagem em geral, as palavras ditas ao seu redor, no convívio familiar. O mesmo acontece com o desenho, a criança imita o modo como observa um indivíduo posicionar-se para assim desenhar, bem como o ritmo e o jeito, não se importando com o que está riscando no papel, daí que surge aquele amontoado de rabiscos. Então, depois ela se apercebe das vagas semelhanças com um objeto e interpreta seu desenho.

Merleau-Ponty, nos Cursos na Sorbonne que aconteceram entre 1949 e 1952, tratou da psicologia da criança e da pedagogia. Cabe ressaltar que os textos produzidos não são de sua autoria e sim dos apontamentos de seus alunos, nesses relatos encontramos uma análise fenomenológica acerca da prática dos desenhos na infância.

Neste curso, o autor faz uma espécie de desconstrução filosófica do raciocínio desenvolvimentista que desdobra a infância em fases, etapas e faixas etárias; elementos primordiais para entender a função do desenho na infância. Ele procura trabalhar a partir de uma fenomenologia da psicanálise, não propondo "outra teoria", mas "outro olhar" para as teorias.

Merleau-Ponty (1990) apresenta-nos os vários estágios do desenho infantil. Com o realismo fortuito, a criança procura representar o objeto como uma totalidade. Incapacidade sintética, desenha cada objeto de forma diferente, considerando seu ponto de vista para diferenciá-los. Com o Realismo intelectual, procura desenhar não só o que pode ver no objeto, mas todas as suas fases, desenha de acordo com sua noção momentânea dos objetos. Já no Realismo visual, representa apenas os aspectos visíveis do objeto, há um aprimoramento de sistema de desenho construído no estágio anterior. 
No texto A dúvida de Cézanne7 (1980), Merleau-Ponty aponta, através das obras deste pintor, a importância de nossa percepção e como ela ajuda na construção do desenho. Cézanne ao tentar retratar sua realidade de mundo (natureza) não utiliza traços definidos ou contornos, ele desenha aquilo que vê, pinta com cores que sua percepção consegue captar, o valor da verdade para o autor reside na tentativa de expressar de forma honesta, o que é posto diante dos sentidos, no texto ele coloca:

\begin{abstract}
Vivemos em meio aos objetos, construídos pelos homens, entre utensílios, casas, ruas, cidades e na maior parte do tempo só os vemos através das ações humanas de que podem ser os pontos de aplicações. Habituamo-nos a pensar que tudo isto existe necessariamente e é inabalável (MERLEAUPONTY, 1980, p. 118-119).
\end{abstract}

Ao analisar as pinturas de Cézanne, o autor compreendeu que sentir, ver e desenhar são experiências, cujas possibilidades visam alcançar o mundo com o corpo. Se o corpo não pode sair do mundo para ver, ele pode se posicionar pela dinâmica de seus movimentos para ver em diferentes ângulos, afirmando que aquele que vê não se apropria daquilo que é visto; apenas se aproxima ou se abre para o mundo.

Ao realizar o desenho na escola, devemos deixar as crianças livres para expressarem suas representações, de forma que suas experiências sejam a base para sua construção, ao direcionarmos essa atividade de forma delimitada e impositiva não criamos espaços para criações, mas sim reproduções. Ao afirmar, por exemplo, que a cor correta para pintar as folhas de uma árvore é verde, não abrimos espaços para os alunos retratarem as folhas coloridas da primavera ou as escuras do outono.

Moreira (1984) aponta que o desenho é uma possibilidade de conhecer a criança através de uma outra linguagem e que o ato de desenhar não é visto como possibilidade de se conhecer, recuperar o ser poético que é a criança. Os desenhos podem proporcionar informações das representações que os alunos possuem sobre determinado assunto.

O educador necessita ter sensibilidade ao planejar essa atividade, pois a extrema mecanização do desenho, que por vezes é ensinado, dirigido e treinado no âmbito escolar, passa a ter caráter reprodutivo, descaracterizando o objetivo de análises, criando cenários iguais a estudantes que apresentam níveis de cognição diferentes.

\footnotetext{
${ }^{7} \mathrm{O}$ autor neste texto propõe um novo método de interpretação de obras de artes e critica enfaticamente a psicanálise freudiana que determina o resultado, com ênfase em uma reflexão inacabada, pois o pensamento, a verdade, a obra, a vida são também inacabadas.
} 
Percebemos a redução do ato de desenhar nas escolas. Talvez a ênfase dada pela escola à escrita possa ser um dos motivos para essa preferência, além da busca de resultados quantitativos nas provas objetivas, as quais as instituições são submetidas. Devemos estimular a prática do desenho, este pode ajuda no desenvolvimento da percepção, emoção, inteligência e outras habilidades.

Se analisarmos o ensino no âmbito formal, perceberemos que os desenhos e outros tipos de expressões não manuscritas, realizadas na maioria das vezes em datas comemorativas, pautadas em procedimentos metodológicos naturalizados, reprodutivistas e instrucionistas, não abrem espaços para questionamentos e reflexões, tanto do processo de ensino, quanto da aprendizagem. É preciso criar estratégias para romper com a forma impositiva que o ensino é ministrado aos alunos.

Por meio da atividade dos desenhos, as possibilidades de reflexões podem ser ampliadas, visto que nossas percepções são diferentes. A objetividade e subjetividade podem ser encontradas nos traços, formas e texturas dos desenhos. Se na fenomenologia a intencionalidade exerce fundamental importância na interpretação do mundo vivido, devemos então estimular práticas que estabeleçam relações de cunho extremamente humano, considerando fundamentalmente as expressões dos alunos sobre uma dada realidade.

\section{FILMES/DOCUMENTÁRIOS, FENOMENOLOGIA E O ENSINO}

Em 22 de março de 1895, o primeiro filme era apresentado, intitulado: La Sortie de l'usine Lumière à Lyon (A Saída da Fábrica Lumière em Lyon), os irmãos Lumiére davam um grande passo no rumo da indústria cinematográfica do entretenimento que, posteriormente, seria considerada como a sétima arte.

Ao longo da história, os filmes foram ganhando elementos como cores, áudios, personagens e cenários. Passando também a exercer novas funções, tornando-se também uma ferramenta educativa, ao constituir-se como veículo que promove debate acerca de diversos temas, oportunizando reflexões sejam de aspectos culturais, históricos, literários, reais e até mesmo políticos.

Quando assistimos a um filme ou documentário, passamos a vivenciar uma história, cujas emoções entre as pessoas são distintas; sentidos como a audição e visão exercem uma conexão que nos possibilitam conceber o outro (personagem), entender e projetar acontecimentos, dessa forma, os filmes podem ser entendidos também como instrumento educativo exercendo fascínio, estimulando a curiosidade e outras emoções. 
Se a fenomenologia é baseada na vivência e esta é parte integrante do processo para a produção do conhecimento, deveríamos então apresentar exemplos de experiências que já ocorreram ou podem ocorrer, despertando nos alunos interesses em assuntos que se pretendem socializar. De acordo com Viana (2010):

\footnotetext{
Por muito tempo, a escola privilegiou o uso da língua escrita, mas a atualidade requer imagens, pois hoje o mundo é da imagem. A invasão da imagem mostra que o estímulo visual se sobrepõe no processo de ensino/aprendizagem, pois a cultura contemporânea é visual. O aluno é estimulado pelas histórias em quadrinhos, videogames, videoclips, telenovelas, cinema, jogos variados, inclusive do computador, todos com apelos às imagens (2010, p. 3).
}

As possibilidades de inserção de filmes/documentários durante uma aula podem proporcionar o alcance de objetivos que seriam almejados na execução de outras metodologias, tais como, esclarecer ou exemplificar um conteúdo, introduzir um assunto no início da aula, propor uma situação problema vivenciada pelos personagens, motivar os alunos em um determinado momento a até mesmo problematizar um conteúdo em que os alunos têm dificuldade de aprendizado.

De acordo com Napolitano (2006, p. 12), “a utilização do cinema na escola pode ser inserida, em linhas gerais, num grande campo de atuação pedagógica”, modificando a prática pedagógica reprodutiva que geralmente é pautada por um único recurso, o livro didático. $\mathrm{O}$ filme/documentário escolhido para se trabalhar durante as aulas necessita apresentar mais que entretenimento, fazendo com que o aluno desenvolva sua criticidade.

De acordo com Ferro (1976, p. 11), um filme oferece inúmeras possibilidades de reflexões e análises "entre o cinema e a história, as interferências são múltiplas, por exemplo: a confluência entre a história que se faz e a história compreendida como relação de nosso tempo, como explicação do devir das sociedades. Em todos esses lugares o cinema intervém”.

Ao utilizar um recurso visual, como filmes/documentários, um dos sentidos que pode ser estimulado é a visão, uma vez que, para Merleau-Ponty, toda sensação pertence a um certo campo, que se comunicará com os demais na medida que os significados sejam concebidos.

Dizer que tenho um campo visual é dizer que, por posição, tenho acesso e abertura a um sistema de seres, os seres visuais, que eles estão à disposição de meu olhar em virtude de uma espécie de contrato primordial e por um dom da natureza, sem nenhum esforço de minha parte; é dizer portanto que a visão é pré-pessoal; e é dizer ao mesmo tempo que ela é sempre limitada, que existe sempre em torno de minha visão atual um horizonte de coisas não-vistas ou mesmo não-visíveis (MERLEAUPONTY, 1999, p. 292) 
Entre os cinco sentidos, um dos mais utilizados é a visão, permitindo ao ser vivo captar informações visuais do meio em que está inserido, processando-as e reagindo aos diversos estímulos. $\mathrm{O}$ olho apresenta diferentes partes, além de estar relacionado diretamente ao sistema nervoso, cujo papel é fundamental na codificação das informações.

No mundo visível, o sujeito que interpreta aquilo que vê e sente não realiza a experiência de ver, se o mundo não for visível para ele. Há um caráter bidimensional que marca a visão, a efetividade da experiência de ver, precisa apelar para uma dimensão subjetiva que exige um olhar para ver as coisas, além do direcionamento particular que concebe a exigência de que as coisas sejam visíveis.

Para Merleau-Ponty, a coisa percebida não é uma espécie de algo visível que se revela a um olhar desprovido de uma presença no mundo. Essa percepção visual consiste na experiência que também ocorre pelo corpo, cujo alcance é concebido pelo jogo de aproximações e distanciamentos, que estabelece condições de vínculos com o mundo.

Através da fenomenologia, pode-se realizar a descrição de forma interpretativa dos fenômenos observados nos filmes/documentários, o que pode gerar debates e reflexões. Os questionamentos e as projeções ganham espaço, criando uma razão participativa, uma vez que esta perspectiva valoriza e estimula a produção de experiências dos alunos, relativizando as compreensões produzidas, pois, reiteramos a ideia de que a compreensão é enfaticamente ressaltada como processual.

Perguntar-se-á como esta realização é possível e se ela não encontra nas coisas uma Razão preexistente. Mas o único Logos que preexiste é o próprio mundo, e a filosofia que a faz passar à existência manifesta, não começa por ser possível: ela é atual ou real, como o mundo de que faz parte, e nenhuma hipótese explicativa é mais clara que o ato mesmo pelo qual retomamos este mundo inacabado para pensar totalizá-lo e pensá-lo (MERLEAUPONTY, 1999, p. 19).

As atividades que envolvem interações e reflexões profundamente humanas fazem parte da fenomenologia merleau-pontyana. É com essa base epistêmica que acreditamos que os filmes/documentários podem ser um instrumento que corroboram o processo cognitivo de construção do conhecimento, se trabalhados de forma a estimular a formação do pensamento científico.

FENOMENOLOGIA, ESPAÇOS NÃO FORMAIS E O ENSINO

Para Jacobucci (2008), espaço não formal é todo aquele espaço onde pode ocorrer uma prática educativa. Sendo estes divididos em dois: os espaços institucionalizados e os 
espaços não institucionalizados. Museus, jardins botânicos, zoológicos, bosques, praças, igrejas, reservas e fábricas são alguns dos locais que apresentam essas características. Lorezentti e Delizoicov (2001) também caracterizam estes espaços:

Os espaços não-formais compreendidos como museus, zoológicos, parques, fábricas,
alguns programas de televisão, a internet, entre outros, além daqueles formais, tais
como bibliotecas escolares e públicas, constituem fontes que podem promover uma
ampliação do conhecimento dos educandos. As atividades pedagógicas
desenvolvidas que se apoiam nestes espaços, aulas práticas, saídas a campo, feiras
de ciências, por exemplo, poderão propiciar uma aprendizagem significativa
contribuindo para um ganho cognitivo (LOREZENTTI e DELIZOICOV, 2001, p.
8).

Giordan e Vecchi (1996) apontam que a escola já não é mais o único lugar de aprendizagem do saber; ela corre até o risco de ser cada vez mais ocultada por técnicas mais atraentes. E ainda alertam que a maior parte do saber científico ensinado durante a escolaridade é esquecida após alguns anos, algumas semanas, se é que foi adquirida alguma vez. Necessitamos refletir o papel dos outros espaços educacionais e como estes podem contribuir no processo de ensino e aprendizagem.

A visita a espaços não formais de educação voltados a práticas de ensino vem aumentando e encontrando receptividade em algumas instituições de ensino, sejam públicas ou privadas. Apesar de muitos profissionais da educação questionarem essa metodologia, ela vem se mostrando eficiente por proporcionar experiências de contato direto com o objeto estudado de forma teórica na educação formal.

Porém, a realização dessas visitas ainda encontra resistência, algumas indagações são muito comuns, há quem diga que essa atividade é meramente ilusória no sentindo de não contribuir para o processo de aprendizagem dos envolvidos; há quem caracterize essa atividade apenas como passeio, o que nos faz analisar como esse processo de aprendizagem ocorre nesses espaços.

Em uma perspectiva fenomenológica, entendemos que é no mundo vivido pela experiência que surge o conhecimento, ou seja, ao realizarmos práticas educativas nestes espaços, criamos um cenário propício a interações, onde experiências cognitivas, afetivas e motoras se ampliam, fazendo com que a atividade incorpore e ganhe significado.

É preciso logo considerar que mundo e corpo estão trançados um no outro, nessa vertente nossas experiências passam por um processo espacial que proporciona captar as percepções, é nesse sentido que "longe de meu corpo ser para mim apenas um fragmento de espaço, para mim não haveria espaço se eu não tivesse corpo" (1999, p. 149). 
Nos desdobramentos do estudo das percepções, Merleau-Ponty sinaliza uma relação de reciprocidade em que corpo e espaço se comunicam. Este processo é subjetivo, porém o espaço que o indivíduo ocupa no mundo real é material, ele é no espaço o que corpo, mundo e percepção produzirão (experiências): "a espacialidade do corpo é o desdobramento de seu ser de corpo, a maneira pela qual ele se realiza como corpo" (1999, p. 206). Afirmando que toda experiência corporal é por definição e princípio uma experiência espacial.

Ao refletirmos sobre a importância do espaço que nos cerca, podemos entender que é através dele que estabelecemos percepções particulares que podem produzir significados para as incertezas que nos movimentam. Para Souza (1997, p. 23), o espaço enquanto lugar "transcende sua condição meramente objetiva, de suporte material para o existir humano (produzir, habitar, circular, amar, guerrear), reaparecendo em plano conceitualmente mais elevado: materialidade dotada de significado. Parte da experiência humana”.

As aulas nos espaços não formais também proporcionam a abordagem dos conteúdos de forma multidisciplinar, como proposto nos PCNs. Os aspectos histórico, geográfico, sociológico e de outras áreas do local podem gerar questionamentos tornando a atividade dinâmica, essa estratégia também pode aguçar nos educandos um olhar profundo a espaços aos quais talvez já conheciam, mas que anteriormente não associaram ou visualizaram algumas especificidades.

Pensemos em uma atividade de trilha que pode ser realizada nestes espaços. Para Vasconcellos \& Ota (2000, p. 37), “a trilha corresponde a um caminho no espaço geográfico, histórico e cultural e passa a ser considerada interpretativa ao ser associada a uma atividade educacional, cujo alvo é interpretar os significados, estimular a construção de conhecimentos". O aluno, no decorrer desta aula, poderá ampliar algumas percepções, pois o trajeto proporcionar-lhe-á recursos diferentes dos habituais. É necessário criar um ambiente de aprendizagem que pode ser no formato de expressão escrita, oral ou, talvez, corporal.

Durante o percurso da trilha, podemos propor uma atividade de audição com o intuito de identificar sons que, a princípio, passariam despercebidos, estimulando a memória auditiva. Merleau-Ponty discute a ideia de sensação colocando-a como algo não necessariamente identificável, no caso da escuta estas são definidas em referência a nossos ouvidos.

O exercício da escuta também pode estar associado às diferentes experiências que vivenciamos e às sensações auditivas que internalizamos. Situam-se em um campo já estabelecido, sendo que este processo de assimilação é subjetivo, desta forma, nossa memória 
auditiva é diferente. Chegaremos assim a depoimentos distintos sobre o que foi escutado durante a trilha, possibilitando reflexões diversificadas.

\section{CONSIDERAÇÕES FINAIS}

A dimensão fenomenológica de Merleau-Ponty se pensada na área de ensino, destaca a importância de entender as nossas compreesões e as dos alunos como expressões incompletas, sucetíveis de retificações a partir da facticidade do ser, nos apresenta o mundo como um laboratório onde são realizadas as experiências de vida e de aprendizagens.

Neste viés a elaboração de práticas pedagógicas voldatas ao ensino, que estimulam o aluno a envolver o corpo nas atividades educacionais o faz perceber o ambiente que o rodeia, dando significado aos fenômenos vivenciados, uma vez que pesquisas indicam que o processo de aprendizagem não corresponde a uma exclusividade da ordem cognitiva, podemos então considerar que as possibilidades de ensino a partir de uma perspectiva fenomenológica são possíveis, sendo uma estratégia que pode ser adotada e ampliada por considerar que nossas experiências são fundamentais na construção do conhecimento, todavia numa perspectiva processual, inacabada.

\section{REFERÊNCIAS}

DARTIGUES, André. O que é fenomenologia? 2 ed. Rio de Janeiro: Eldorado, 1973.

FERRO, Marc. Cinema e História. Rio de Janeiro: Paz e Terra, 1992.

FRÓIS, Kátia P. Revisão da percepção da arquitetura em Bruno Zevi, Christian Norberg-Schulz e através de Heidegger até a possibilidade fenomenológica de MerleauPonty. OLAM. Ciência e Tecnologia, Rio Claro, v. 1, n. 2, p. 123-152, nov, 2001.

GIORDAN, A.; VECCHI, G. As origens do saber: das concepções dos aprendentes aos conceitos científicos. 2 ed. Porto Alegre: Artes Médicas, 1996.

HEIDEGGER, M. História do conceito de tempo: Prolegômenos. Trad. Theodore Kisiel, Bloomington, Indianapolis: Indiana University Press, 1992.

HUSSERL, E. A crise da humanidade europeia e a filosofia. Porto Alegre; EDIPUCRS, 2008.

JACOBUCCI, Daniela Franco Carvalho. Contribuições dos espaços não formais de educação para a formação da cultura científica. Em extensão, Uberlândia, v. 7, 2008.

LORENZETTI, Leonir; DELIZOICOV, Demétrio. Alfabetização científica no contexto das séries iniciais do ensino fundamental. Ensaio - Pesquisa em educação em Ciências, Belo Horizonte, v. 3, n. 1, p. 5-15, 2001. 
MARIN, Andréia Aparecida. Pesquisa em educação ambiental e percepção ambiental. Pesquisa em Educação Ambiental, São Carlos; Sorocaba-SP: UFSCar; Rio Claro-SP: UNESP/IBRC; Ribeirão Preto-SP: USP/FFCLRP, v.3, n.1, p.203-222, jan/jun. 2008.

MERLEAU-PONTY, M. Fenomenologia da percepção. Trad. Carlos Alberto R. de Moura. São Paulo: Martins Fontes. Livraria Martins Fontes Editora Ltda. 1999.

. Merleau-Ponty na Sorbonne: resumo de cursos: 1949-1952: Filosofia e

Linguagem. Trad. Constança Marcondes César. Campinas, SP: Papirus, 1990a. Merleau-Ponty na Sorbonne: resumo de cursos: 1949-1952: Filosofia e

Linguagem. Trad. Constança Marcondes César. Campinas, SP: Papirus, 1990b.

. A Estrutura do Comportamento. Trad. José de Anchieta Corrêa. Belo Horizonte, MG: Interlivros, 1975. 1980. A dúvida de Cézanne. De: Textos selecionados. São Paulo: Abril Cultural,

MOREIRA, V. O Método Fenomenológico de Merleau-Ponty como Ferramenta Crítica na Pesquisa em Psicopatologia. Psicologia: Reflexão e Crítica, 17(3), p.447-456, 2004. MOREIRA, Ana Angélica Albano. O espaço do desenho: A educação do educador. São Paulo: Edições Loyola, 1984.

NAPOLITANO, Marcos. Como usar o cinema em sala de aula. São Paulo: Contexto, 2003.

SOUZA, Marcelo Lopes. Algumas notas sobre a importância do espaço para o desenvolvimento social. Rio de Janeiro: Garamond, 1997.

VIANA, M. C. V. O Cinema na Sala de Aula e a Formação de Professores de Matemática. Mini-curso oferecido aos alunos do Curso de Matemática na UFRRJ. Dia de Atividades Acadêmico-Científico-Culturais. 18 de maio de 2010. Seropédica- RJ.

VASCONCELLOS, J. M. O. Avaliação da visitação pública e da eficiência de diferentes tipos de trilhas interpretativas no Parque Estadual Pico do Marumbi e Reserva Natural Salto Morato - PR. Curitiba. 1998. 141fls. Tese (Doutorado em Ciências Florestais). PósGraduação em Engenharia Florestal, Universidade Federal do Paraná.

OTA, S. Atividades ecológicas e planejamento de trilhas interpretativas. Maringá: Departamento de Agronomia, UEM, 2000 (mimeo). 